\title{
How Public Are We? Coverage of Sociology by the Associated Press
}

\author{
Catherine Siebel $•$ Katherine Clegg Smith
}

Published online: 4 September 2009

(C) Springer Science + Business Media, LLC 2009

\begin{abstract}
The recent and prolific attention to public sociology has involved a great deal of theoretical debate about its merits, flaws, and potential future within the discipline. Despite the loud call for becoming more public, existing research on the discipline lacks both an empirical understanding of where we are as well as a methodological rubric to guide future inquiry. This project explores one outlet for public sociology - the press - as a starting point for this line of research. Through an investigation of Associated Press stories featuring sociology and sociologists, we seek to provide a baseline for consideration of public sociology efforts by describing the current state of how our discipline and its members are portrayed in the press. Further, based on our findings we provide some insights for future research.
\end{abstract}

Keywords Public sociology $\cdot$ News media $\cdot$ Associated press $\cdot$ Wire stories

\section{The Extended (and Extensive) Call for Public Sociology}

Since Michael Burawoy's now-renowned efforts that culminated in his 2004 American Sociological Association (ASA) Presidential address, interest in advancing public sociology has burgeoned throughout the discipline: within just

C. Siebel $(\square)$

Department of Sociology, Northeastern Illinois University, 5500 North St. Louis Avenue,

Classroom Building Room 2090, Chicago, IL 60625-4699, USA

e-mail: C-Siebel@neiu.edu

K. C. Smith

Department of Health, Behavior and Society, Johns Hopkins Bloomberg School of Public Health, 624

North Broadway, Baltimore, MD 21205, USA 
a few years, the ASA formed the Task Force on Institutionalizing Public Sociologies, a professional conference has used this concept as a theme, ${ }^{1}$ and at least six separate journals have devoted a full issue to the topic. ${ }^{2}$ At this point then, it seems that it has been decided: public sociology is here to stay.

However, despite the assertion that sociology should be made public, thus far there has been little research of how public we are, let alone how public we have been. Sociology has yet to produce a baseline from which to measure future efforts. This is true across the board - not only are we missing a body of empirical knowledge about the current state of public sociology, but the call for such a development has been muted at best. To that end, this project contributes an exploratory examination of one facet of public sociology by asking the question, To the extent that the news media both informs and reflects our current understanding of public issues, where does Sociology fit?

At its most basic, Burawoy's (2005) conception of public sociology is its "concern for the public image of sociology, presenting findings in an accessible manner, teaching basics of sociology and writing text books" (p. 271). This call, although met with mixed criticism, has actively engaged scholars for the past several years, generating questions not just about the role of sociology in the public sphere, but about academia as a whole.

To be sure, neither the strength of Burawoy's call nor the perceived importance of public sociology are universally agreed upon. In the first instance, Brady (2004) has pointed out that Burawoy's model for public sociology includes neither concrete proposals for institutional change nor tangible measures of success. Furthermore, as several scholars have argued, sociology's foray into the public is not unproblematic. Ericson (2005) asserts that public sociology may result in a loss of professional autonomy among sociologists, and several scholars (Brady 2004; Tittle 2004; Nielsen 2004) have charged that Burawoy's plans for public sociology implicitly attempt to promote his personal political stance, rather than that of the profession in general or the ASA in particular. Finally, although largely absent from the discussion, we would add as a criticism that it is unclear what "problem" public sociology addresses.

\section{What We Know So Far (and What We Don't)}

With the public debate about public sociology in mind, this project aims to explore one facet of this issue-specifically, sociology in the news. Burawoy (2005) conceptualizes public sociology as an endeavor that "brings sociology into a conversation with publics, understood as people who are themselves involved in conversation" (p. 263). Almost by definition, then, public sociology includes (although is not limited to) engaging with the news media. Media engagement

\footnotetext{
${ }^{1}$ The theme for the 2008 Annual Meetings of the Midwest Sociological Society was "Making Sociology More Public".

2 Social Problems in February of 2004, Social Forces in June of 2004, Critical Sociology in Summer of 2005, The British Journal of Sociology in 2005, The American Sociologist in both 2005 and 2007, and an upcoming issue of Canadian Journal of Sociology.
} 
includes letters written to the editor as well as news coverage of empirical research and-although unstated - sociologists who are called upon in their role as expert to speak to a current event or other news story. These efforts have come to be known, using Burawoy's typology, as "traditional" public sociology in comparison with other, more interactive types where the public is both immediate and visible.

\section{Social Science in the News}

The literature shows that social science's interest in empirically exploring news engagement with social scientific knowledge has been scattered, at best. By far the most comprehensive examination of the subject of social science news is Weiss and Singer's (1988) book, Reporting of Social Science in the National Media. The authors' three-pronged methodological approach included coding social sciencefocused news stories (newspaper, magazine, and television), and interviewing both the journalists who produced these stories and the social scientists whose research was being reported. Their findings stressed the crucial "process of negotiation between reporters and their scientist sources" (p. 226), and they argued persuasively that the social science research reported by the media "related to currently newsworthy topics" (p. 235). In other words, social scientists cannot sit and wait for the press to come to them; rather, the process of integrating academic research into news coverage relies on timely and proactive efforts. Success in this area varies widely, however, even within the social sciences. Consequently, although studies of social science have typically included sociology, the need remains to critically consider sociology's stand-alone role in the press. This is especially the case if we are to pursue public sociology efforts.

\section{Sociology in the News}

One reason for separately examining sociology is that, like it or not, sociology is competing with other disciplines to explain phenomena such as social interaction, structural inequality, occupational trajectories, and cultural trends. Most notably, economists have been identified as public intellectuals whose message has come to resonate with the public. Weiss and Singer (1988) argue that "reporting of economics in the media is made up largely of items that have become familiar-statistical indicators, such as cost of living and unemployment statistics, reviews of current conditions, predictions by economists about the future state of the economy and similar items that have become routinized through repetition." (p. 110) To put it more bluntly, economics created a set of indicators - the health of 'the economy' over which they are the automatic and unquestioned experts.

An informal analysis of news patterns suggests that Associated Press journalists, at least, call upon economists far more frequently than sociologists (Table 1).

As this table suggests, despite being only slightly larger in membership, economics' AP coverage outstrips that of sociology by a factor of more than 16 . The prevalence of economists in the 20 years since Weiss \& Singer's analysis has continued, if not exacerbated. Small (2008) argues that economists are expanding their purview by researching traditionally sociological topics. Never- 
Table 1 Number of AP stories relative to professional association members

\begin{tabular}{lll}
\hline Discipline & $\begin{array}{l}\text { Number of AP stories, } \\
1 / 1 / 98-1 / 1 / 2008^{\mathrm{a}}\end{array}$ & $\begin{array}{l}\text { Number of Prof. Association } \\
\text { Members, 2008 }\end{array}$ \\
\hline Economics & 38,936 & 17,096 \\
Sociology & 2,425 & 14,421 \\
\hline
\end{tabular}

${ }^{\text {a }}$ Search Terms: Economics, Economist; Sociology, Sociologist, Sociological

${ }^{\mathrm{b}}$ Professional Associations: American Economics Association; American Sociological Association

theless, although some researchers point strongly to the discipline's dearth of public attention, an empirical inquiry into sociology's location within the public arena remains lacking.

This is not to say that the place of sociology in the news has not been considered at all. However, to the extent that sociology's distinctive place in the news has undergone any type of academic scrutiny, it has largely been from the first-person perspective of sociologists describing their experiences with journalists (e.g., Adler 1984; Best 1986; Dunning 1994; Ortiz 2007; Stacey 2004). In some cases, these analyses have been discussed under the rubric of public sociology, while others have simply recounted their own experience and perspective having served as a news source. As an example of the former, Vaughan (2006) wrote about her public sociological presence when her expertise on organizational failure was called upon, both by the press and by NASA itself, in the days, weeks, and ultimately months following the Columbia disaster. Serving in the capacities as professional, policy, critical, and public sociologist, Vaughan described in detail her experience crossing the boundaries of these areas of her work. Echoing Ericson's (2005) concerns for loss of sociological autonomy at the hands of the press, Vaughan wrote, "[O]ften, my own experience was one of losing control over my ideas and, sometimes, in television, outright manipulation and exploitation." (Vaughan 2006, p. 360).

From the scant amount of literature in the area of sociology in the news, a few lessons are useful to highlight in the context of the present analysis. The first, in fact, is that the literature is scant. Although some research has included sociology in their exploration of how social science is presented in the news, there has been no systematic appraisal that is discipline-specific. This gap covers a relatively wide swath. In the first place, we have no sense of the volume of news coverage that sociology receives, either by itself or in relation to other disciplines. Such a measure would indicate the degree to which sociology is considered public at all. Further, as yet we do not have a sense of the areas of news coverage with which sociology is associated - under what circumstances are sociologists called upon to serve as experts? What research methods resonate with the media?

The second note to take away from the existing literature is that to the extent that there has been any type of critical exploration of sociology in the news, it has been presented from a first-person perspective, rather than that of a researcher. This trend has the unintended effect of placing strong emphasis on the sociologist's perspective, 
to the exclusion of the journalist's. As with any other new topic of inquiry, there is a point at which inquiry ought to shift from personal narrative to a series of empirical studies that advance a theoretical understanding of the topic. Now is that time for public sociology.

\section{Structural \& Cultural Barriers}

Underlying the public sociology movement is the sense that sociology is not public enough. In the case of "traditional" public sociology, then, this perception translates into the need to understand why sociology in general, and sociological studies in particular, fail to be deemed newsworthy. A review of the literature suggests that this phenomenon is a function of structural demands on the professions of both sociology and journalism, as well as cultural constraints constructed by sociologists, journalists, and the public alike.

\section{Sociology}

Whereas the key premise of most social science is that knowledge is constructed, and can never be 'value free', the underlying assumptions of journalism are precisely the opposite-that by presenting 'facts' they can research a level of objectivity in their reporting that precludes judgment and bias. (Fenton et al. 1997, p. 3)

The first area of literature focuses on what Merton and Wolfe (1995) dub the "supply side"; the production of sociological knowledge. The research that helps explain sociology's public role can be organized into three major areas: our message; our engagement with the public; and the demands of our professional culture.

\section{Our Message}

Inherent to sociology's message are elements that present significant hurdles to making their way into the press. The first is our subject matter; to the extent that sociology has a unified subject, that subject would be "society" — which, as topics go, is both broad and diffuse (Becker and Rau 1992), and thus not particularly well suited to selling newspapers. Further, the discipline's theoretical, methodological, and substantive schisms add to the elusive nature of sociology. McNamee and Willis (1994) suggest that,

\footnotetext{
“[...] disciplines such as sociology have a large number of independent and autonomous schools and perspectives with their own separate organizations and associations. [...] There may be a high level of integration within these specialty areas and organizations but a low level of integration across the discipline as a whole." (p. 401)
}

In other words, a consequence of sociology's eclectic nature is that the general public grapples with trying to get a handle on what sociology is. Economists may easily be understood as experts of "the economy" (an easily identifiable, if 
amorphous, concept), psychologists are set to work on "behavior" and "the self", and yet the role of sociologists remains obscured by virtue of their message.

Ironically, this obscurity is compounded by the fact that sociologists research phenomena with which the lay public has considerable everyday experience and therefore considerable opinion-e.g., marriage and family, labor, health and medical issues. This frequently leads people to assume that our findings are "common sense", rather than the result of stringent empirical work.

Beyond the nature of our message, sociologists have additionally criticized themselves for writing in prose that is completely opaque to people outside of the discipline. Best (2004), for example challenges sociologists to "translate" research for the lay public: "[W]e must be prepared to repackage what we write for broader consumption. [...] The shorter the piece, the easier it is to read, and the simpler the message, the larger the audience." (p. 157) Implied here is the tension between making our research more accessible to the public and the risks inherent in providing over-simplified content.

\section{Our Engagement with the Public}

This tension represents a second hurdle to sociology's public image: our members, largely from force of habit, are often reticent to subject themselves to public attention. This may be from force of habit: "Academics are used to thinking of publication as their goal, as though once our work gets into print, we can sit back and wait to be noticed." (Best 2004 p. 156) As others have noted, this "habit" has largely been borne out of institutional factors; there is typically no professional reward in academia for making one's findings more "public" (discussed in more detail, below). Indeed, there is almost the opposite: tenure is granted to those who publish, not those who publicize.

Moreover, the few sociologists who have written about their experience with the press have discussed the various ways in which their messages have been skewed by the media (Adler 1984; Beck 2005; Best 1986; Dunning 1994). Stacey (2004), for example, recounts her experience at the hands of the news media in her role as an expert on family and marriage rights: "Sound-bite social science cannot accommodate complexity, nuance, ambiguity, or uncertainty - the fundamental features of critical reason and intellectual inquiry" (p. 141).

This first-person observation has empirical support: Fenton et al. (1997) found that "the fear of being professionally undermined and the skepticism towards their public role are two of the factors that lead to the public voice of social scientists being subject to the self-insulations of a profession." (pp. 8-9) Ortiz (2007) argues that sociologists lack both the preparation and the skills for dealing with the mass media. This, then, may be a question of re-education for professional sociologists, and offering some training in how to deal with the press may alleviate the concerns of scholars.

As such, a self-perpetuating cycle emerges: sociologists are not provided with the preparation for dealing with the media; as a result, their early interactions with journalists leave them with a sense that their ideas were hijacked, leading them to avoid future contact with the press; and as a consequence of these experiences, they fail to provide institutional support for their students (aka, future sociologists) to acquire the necessary skills for dealing with the media. 


\section{Professional Culture}

A third element of sociology's relatively low participation in the public forum may have to do with the structural constraints of both the discipline and the institution of academia. Engaging with the public is institutionally discouraged in academia, and faculty promotion and tenure exist within the traditional trinity of the professionresearch, teaching, and service-to the implicit exclusion of other activities. Furthermore, as Jacobs and Townsley (2004) argue, "media intellectuals" experience suspicion and disadvantage among other academics.

A correlate of the first point is that there are no professional outlets for disseminating empirical research on public sociology - in other words, a journal that legitimates these efforts as a respectable part of the discipline. ${ }^{3}$ The corresponding uneven interest within the discipline means that scholars trying to engage in public sociology are marginalized, relegated to special issues of journals with other, competing aims.

Another hurdle is sociology's passive professional role in providing the news media with content. The business of writing press releases that are news-ready has been around for decades, and its success in generating news coverage is well-documented (e.g., Woloshin and Schwartz 2002). Some journals exemplify a well-oiled machine whose multiple staff members feed the press a reliable, steady stream of news content. The Journal of the American Medical Association (JAMA), for example, provides regular, weekly offerings that include several print releases, video releases (for use by local news stations), report videos, and media briefings. Other medical journals have followed suit: Woloshin and Schwartz (2002) found that most medical journals (rather than organizations) routinely issue press releases on recent articles.

Sociology stands in sharp contrast to this model, a fact which has both practical and epistemological consequences. The practice of promoting sociological research to journalists was almost non-existent until 2006, when the ASA hired their first Media Relations Officer to work on behalf of all eleven ASA-sponsored journals. This initial, if belated, organizational step has resulted in changes to the website, including a section entitled "For Journalists" that provides, at irregular intervals, an average of 3.75 press releases per month for journalists to download and use. ${ }^{4} \mathrm{~A}$ direct consequence of this organizational structure is, of course, that fewer sociological articles make their way into the news.

Furthermore, as far as the press is concerned, there are no obvious journal (Evans 1995) that serve as the voice of sociology. In their analysis of how news on cancer research is disseminated, Smith et al. (In Press) found that journalists focus - almost exclusively — on research coming from flagship journals such as JAMA and the New England Journal of Medicine. This finding echoes other research which suggests that prestige begets prestige, such that traditional markers of good science inside the journal are less important than the name on the front cover (Callaham et al. 2002).

\footnotetext{
${ }^{3}$ We are not referring to a publication like Contexts, whose aim is to publicize sociological research; rather, we are specifically thinking about a journal focusing on empirical examination of public sociology efforts.

${ }^{4}$ Between March 2008 and March 2009.
} 
A parallel concern is the extent to which sociological research is considered a science. McNamee and Willis (1994) identified several indicators of "big science research" (p. 412) used by the press. Three are germane to this discussion: the average number of authors per article; acknowledgement of external support; and extent of quantitative analyses. To the extent that such markers indicate the cache of science, sociology then appears (at least on the face of it) to be less "scientific" than other, more traditional sciences. Additionally, in a comparison of news coverage of the hard and social sciences, Evans (1995) identified a series of tactics that undermine the perception of social sciences as a legitimate science. Their findings suggested that that the Science sections of major newspapers tend to focus almost exclusively on natural science, thereby undermining the perception of social science as "science". Furthermore, social researchers are inconsistently presented as scientists, and social science journals are less likely to be mentioned in the popular press than hard science pieces. It is important to note that separately, each of these devices mitigates the "scientific" aspect of social research, but the combination of these tactics can devastate sociology's quest for external legitimacy.

Implicit in these markers of "science" is the issue of external funding. As Merton and Wolfe (1995) outline, social science funding decreased dramatically during the Reagan administration, a trend that continued well into the mid-1990s. Correspondingly, the pressure for sociologists to pursue funding is relatively low compared with disciplines such as biological science and public health, both in terms of number of funded researchers and amount of funding dollars. This is partially due to the fact that most baccalaureate institutions, where sociology is prominent, lack the infrastructure to accommodate the administrative demands of external grants (Petersen et al. 2008).

This lack of institutional support, which in turn reduces the likelihood of receiving external funding, is particularly consequential for public engagement. Indeed, the demands of external support are such that funders are increasingly expecting - if not insisting - that grantees disseminate their research via the mass media. As Fenton et al. (1997) argue, "researchers are facing pressure [from funders] to demonstrate value for money, policy relevance and accountability." (p. 2) In this way, the nature of our profession is itself a barrier to becoming more public; our lack of external funding, and consequent lack of pressure to publicize, alleviates the need to become more public.

Sociology then, faces a number of "supply-side" barriers to becoming more public: the diffuse nature of our message, as well as the perception that our subject matter is "common sense"; the profession's lack of institutional support for public sociology efforts, and the resulting reluctance to participate in the public forum; and a profession that lacks the markers of legitimate "big science".

\section{Journalism}

Sociology is only one half of the equation, however. While our discipline's message, professional emphases, and institutional demands all influence the extent to which we make our way into the news, journalism has its own institutional and cultural factors that guide its gate keeping - or "demand side"-decisions. 


\section{Professional Demands}

Pragmatically speaking, journalists' time to develop a story is limited; they need messages that are sufficiently timely and succinct for a press release. Journalists, then, rely on a standard formula in determining what counts as good science: “... journalists are using the $N$ of the study as a quick heuristic for judging the accuracy and value of the research." (Schmierbach 2005, p. 283) As a result, journalists perceive that studies with a larger $N$ are of higher overall quality than those with lower numbers of respondents. While there is room elsewhere to debate the epistemological ramifications of this convention, for now it is sufficient to point out that the nature of both our empirical mandate and our typical funding structures are such that many (though certainly not all) sociological studies simply lack the cues that journalists search out for news stories.

Beyond the professional constraints in physically producing a news story, standard news stories employ the fair practice doctrine, in which every issue is allowed two sides. Weiss and Singer (1988) conclude that when social science findings are at odds with one another, the media take one of two approaches. More commonly, "the findings were presented as discrete, disconnected bits, with no reference to the conflicting research". The second approach is to highlight the conflict, "but with no effort to reconcile the discrepancy" (p. 256). Consequently, qualifications or equivocation of issues - in other words, the elements of nuancetend to be removed altogether. Similarly, an analysis of political scientists in the news found that the "game frame" dominated the discourse, such that political topics were routinely presented as a series of horse races (Brewer and Sigelman 2002) rather than issues with shades of meaning. To the extent that sociology is both explicitly critical and analytically complex, our message is likely to be less attractive to journalists than that of other disciplines.

\section{News Frames}

A second explanation for journalists' reticence to focus on sociologically-themed stories may be the disconnect between traditional news frames and sociology's underlying assumptions. Per the literature on news frames, the media generate stories that fit within, and in turn reproduce, certain narratives (Schmierbach 2005). One of the more dominant frames within news is the individualism frame (e.g., Dorfman et al. 2005; Eisinga et al. 1999); the news media tend to highlight stories where people are singularly responsible for, and individually overcome, their circumstances. The individualism frame resonates with both journalists and readers, thereby increasing the likelihood that these types of stories will be produced, consumed, and thus reproduced. This cycle presents a challenge to the theoretical underpinning of our discipline, which posits that nearly every aspect of an individual's life is guided by broader social phenomena that can't be overcome by force of will.

\section{Journalist Training}

As the discussion on the heuristics used by journalists suggests, training strongly influences the propensity to cover sociology in the news. On the whole, journalists 
are not trained in social scientific methodology, a fact which may play a role in generating the perception among journalists that sociology doesn't matter as a science (Evans 1995). Dunwoody's (1980) early study on science reporters highlights this pitfall: one interviewee commented, "I'm not very well equipped to evaluate sociology,' [...] 'but it can't hurt anybody so I figure it's not going to do too much damage if I get it a little screwed up."' (as quoted in Dunwoody 1980, p. 20) This quote exemplifies the perception that sociology isn't 'real' science, and further emphasizes the need to teach social science alongside natural science to future journalists.

In sum, this literature review highlights a few salient points about the role of sociology in the news. First, despite the numerous and extensive calls for sociology to become more public, empirical research of the phenomenon is both scattered and thin. Second, the ancillary research suggests a set of interrelated institutional and cultural barriers within both sociology and journalism that prevent sociologists from successfully disseminating research to the public.

\section{Methods \& Data}

\section{Research Questions}

The existing research provides a few key areas which an empirical study of traditional public sociology might pursue. We begin with the question of:

\section{RQ1. Under what circumstances is sociological expertise called upon in the news?}

While broad, this question opens the door to considering other questions posed by the literature. First, in light of McNamee \& Willis's observations on the splintered nature of sociology, one might usefully ask about the extent to which sociology's various subfields are evenly represented in the news. To that end:

$1_{a}$ Do certain sociological subfields garner more press attention than others? If so, which ones?

In addition to the substantive areas being represented, existing literature on science in the media reminds us that some methodological conventions are more likely to cue a journalist to the study's newsworthiness. In this vein, then, we additionally pose the following questions:

$1_{b}$ Under what circumstances does a sociological study generate the news story?

$1_{c}$ What methodologies are most represented in news coverage of the discipline?

Thus far, our research questions are directly toward the research itself, rather than the researchers. The question remains about whose research or expertise becomes public. We therefore also ask:

$1_{d}$ What geographic or institutional locations produce more sociological coverage? 
A secondary point concerns how sociology as a discipline is presented in the press. Thus, our final question:

\section{RQ2. Beyond research expertise, under what circumstances are sociology and sociologists mentioned?}

With these questions as a starting point, we thus begin an initial exploration of sociology's role in the news media.

\section{Data Collection \& Analysis}

To answer these questions, this analysis uses data from the Associated Press (AP). Clearly, there are good reasons for investigating wire service articles in an attempt to further our understanding of modern news consumption. The AP, which touts itself as "the largest and oldest news organization in the world" epitomizes global news. AP's 243 news bureaus produce stories for more than 1,700 American member newspapers, 5,000 radio and television subscribers, and millions of audience members (Associated Press 2009).

The decision to analyze Associated Press stories breaks with academic convention, which routinely focuses on the prestige press in general and The New York Times in particular. Our methodological choice is grounded in literature pointing to a relatively recent but important shift in the news media industry. The 21 st century ushered in stark changes resulting from global media enterprises (BoydBarrett and Rantanen 2000), and media ownership has been concentrating since the mid-1990s (George 2001), resulting in personnel cuts that force news outlets to generate fewer local stories. The consequence of these trends has been an increased (and increasing) reliance on wire stories (Luttbeg 1983; Soderlund et al. 1991) among newspapers, radio stations, and televised news. Early media scholars argued persuasively that a full understanding of news content cannot be complete without taking into account the role of wire services (Danzger 1975), especially given many newspapers' increasing reliance on them (Soloski 1979; Glasser et al. 1989).

Indeed, wire services generate and disseminate much of the news we encounter in a given day, particularly among non-locally owned newspapers and Internet news sites such as Yahoo! News (Patterson 2005). Wire agencies have recently been argued to "set the agenda for what international stories [and] other media choose to carry" (Patterson 2005, p. 152). The growing ubiquity of wire stories strongly suggests that their influence over local news will continue to grow in the future. These conclusions by media researchers convinced us that AP stories were the strongest theoretical and methodological choice for this research.

Data were collected from an electronic archive of Associated Press (AP) articles. We included all articles published by the AP in 2006 that include the words "sociology", "sociologist", or "sociological" in this year." This search strategy produced a total of 184 articles.

The two authors collaborated to inductively create the coding categories of interest by repeatedly reading and re-reading small samples of articles. Once this

\footnotetext{
${ }^{5}$ In the case where more than one version of the same release appeared in the same day, the latest release was kept and the others excluded.
} 
process was completed, we developed a first draft of a coding scheme that relied on mutually exclusive categories. We then independently applied this coding scheme to more small samples of articles and compared our coding, refining the instrument as we progressed until we reached consistent consensus. At the point where we agreed that the instrument was sufficiently valid and reliable, each author coded one half of the articles, with any problematic articles being coded collectively.

\section{Coding Categories}

This analysis included twenty-two coding categories measuring size, location, nature of sociological research, and details about specific sociologists.

First, we recorded the basic details of size and geographic location of the news story. As a measure of size, we recorded the word count of the release that was provided by the AP. We also recorded the dateline (i.e., where the news event occurred), and whether or not the story was international or domestic. Additionally, in every article where a specific sociologist was mentioned, their name and institutional affiliation were recorded. News topic/news event was also coded in every article.

Our choice of key words (sociology, sociologist, sociological) resulted in two basic types of stories: those that were either driven by sociological research or asked a sociologist to comment upon a news event; and those where the "sociological mention" was absolutely ancillary to the article. Both types of articles are important in exploratory research such as this, although they require separate analytic treatment. Sociology-focused articles were those that could help us answer RQ1, Under what circumstances is sociological expertise called upon in the news?. More ancillary mentions were fell under RQ2, Beyond research expertise, under what circumstances are sociology and sociologists mentioned?

To distinguish between these two types of articles, we initially coded for sociology focus, a dichotomous measure that recorded whether or not sociological research was somehow featured in the article. Sociology-focused articles were then coded for up to two research themes, as well as whether or not sociological research was driving the article, whether or not a methodology was mentioned, and if that methodology was qualitative or quantitative in nature. Among articles that were not sociology-focused, we recorded information about the role of the sociologist in the news.

\section{Findings}

\section{All Articles}

We identified two noteworthy geographic findings when considering all the articles. The first is to that sociology is relatively prevalent in international stories: nearly a third of news releases $(n=58,32 \%)$ relate to international people and events. Seventeen of the 18 articles about politics were international, suggesting that sociologists' status as experts of international political issues far outstrips that of the United States.

The second is to note the institutional affiliation: just over half of all the articles $(53.8 \%)$ of the articles included an institutional affiliation. Among these, Duke 
University was represented in five articles; and Columbia and Princeton Universities appeared in four wire stories apiece. Remaining institutions were mentioned only once. The slight prominence of research from these institutions may reflect any one of a few factors. A possible explanation is that the prestige of these universities makes the research produced there more newsworthy. Alternatively, these schools may have stronger public relations affairs departments. A third possibility is that these researchers may have already been in the journalists" "Rolodex", so a call from the researcher would be more likely to secure coverage.

In the same vein, it is worth noting that several sociologists were quoted in more than one AP release, suggesting the same "Rolodex" phenomenon. Of the 129 articles that referenced a sociologist, twenty-eight (22\%) referenced the same source in more than one article. Three of these were a result of non-sociological activities (e.g., protesting, dealing with university scandal). The remaining ten, however, served as sources more than once, accounting for 21 different articles. In each of these cases, the sociologist had been identified as having a clear area of expertise (e.g., Russian politics, mega churches, Mexican immigration).

\section{Sociology-Focused Articles}

Exactly two-thirds $(n=122)$ of the articles included either discussion of sociological research or a direct quote from a professional sociologist (i.e. sociology-focused). When looking at the research themes that resonated with journalists (see Tables 2 and 3), we see a specific historical moment reflected in these articles; among the most common themes were crime \& policing; religion; war/military; immigration; race; and politics.

The predominance of crime \& policing is perhaps unsurprising, given the concurrent upswings in the prison industry as well as the study of criminology, often as a subfield within sociology. In one example, a professor at Dominion University was asked to comment on a news story about a recent postal workplace massacre by a female employee. An excerpt reads, "Like other experts, [Sociologist] Danner has noticed news reports in recent years suggesting that violence perpetrated by young women was becoming more common, but she described this as an artificial

Table 2 Descriptive variables

\begin{tabular}{llrl}
\hline & & N & \% of all articles \\
\hline Nomenclature & Sociology & 98 & 53.3 \\
& Sociologist & 78 & 42.4 \\
& Sociological & 8 & 4.3 \\
Geography & International & 58 & 31.5 \\
& Byline & & \\
Sociology-focused? & Yes & 122 & 66.3 \\
Research-driven? & Yes & 17 & 9.2 \\
Methodology mention & Qualitative & 1 & 0.5 \\
& Quantitative & 12 & 6.5 \\
Institutional & Yes & 99 & 53.8 \\
affiliation? & & & \\
\hline
\end{tabular}


Table 3 Frequency distribution of research theme

${ }^{\mathrm{a}} \mathrm{N}$ is divided by 122 (number of sociology-focused articles). Total number of themes adds up to more than 122 due to the fact that every article could be coded for up to two themes
N Percent of sociology-focused articles ${ }^{\mathrm{a}}$

\begin{tabular}{|c|c|c|}
\hline Politics & 18 & 14.8 \\
\hline Religion & 17 & 13.9 \\
\hline Crime \& policing & 16 & 13.1 \\
\hline Immigration & 13 & 10.7 \\
\hline War \& military & 13 & 10.7 \\
\hline Race & 12 & 9.8 \\
\hline Gender & 11 & 9 \\
\hline Social class & 8 & 6.6 \\
\hline Other & 8 & 6.6 \\
\hline Culture & 7 & 5.7 \\
\hline Demographics & 6 & 4.9 \\
\hline Family & 6 & 4.9 \\
\hline Education & 5 & 4.1 \\
\hline Health \& medical & 5 & 4.1 \\
\hline Sports & 5 & 4.1 \\
\hline Work & 5 & 4.1 \\
\hline Children \& youth & 4 & 3.3 \\
\hline Media & 4 & 3.3 \\
\hline Sexuality & 4 & 3.3 \\
\hline Ethnicity & 3 & 2.5 \\
\hline Consumption & 2 & 1.6 \\
\hline Economy & 2 & 1.6 \\
\hline Housing & 2 & 1.6 \\
\hline Total & 176 & \\
\hline
\end{tabular}

'hysteria' largely unsupported by statistics." (299) This excerpt is one example of sociological expertise being recognized and presented as relevant for providing context and explanation for crime statistics (or public perception of crime statistics).

As mentioned previously, the articles focused on politics typically came from international in settings and events. One example comes from Chile, who swore in their first woman president in 2006. In response, Teresa Valdes of the Latin American Faculty of Social Science, commented that "Gender inequities, discrimination and exclusion of women have historically been very deep in Chile." (261) A second example came from Israel, where a discussion of Ariel Sharon's power in shaping the Israeli culture led Nachman Ben-Yehuda of Hebrew University [a sociologist] to comment that, "Sharon has created his own mythology." (291)

Fourteen percent $(n=17)$ of sociology-focused articles were driven by sociological research - that is, a research piece was the impetus for the news story. These articles were not limited to a certain area of sociology, but rather spanned topics as diverse as class-driven obesity trends among teenagers, Houston residents' shifting attitudes toward Katrina victims, and the dominance of Korean women in the Ladies Professional Golfing Association (LPGA). 
Twelve research-focused stories mentioned a methodology, eleven of which referred to quantitative methodology. ${ }^{6}$ For example,

"The institute controlled for major health shocks over the study, and measured respondents' level of neurosis, to control for the tendency of highly neurotic people to give low ratings of their mental and physical health"

Consistent with both Weiss and Singer (1988) who identified the proliferation of surveys as part of the social science/media landscape, and Schmierbach's (2005) findings regarding journalists' use of an $N$ of a study to determine its value, the methodology that seemed to resonate most with journalists - that is, the one they described most often - was quantitative, survey research:

"The latest Pew report, issued Wednesday, was based on random telephone surveys conducted in February and March of 2004 and 2005. Each year's survey involved about 2,200 adults and had a margin of sampling error of plus or minus two percentage points."

While many stories seemed to use quantity as a heuristic for quality, others featured assertions and conclusions from sociologists without even citing a specific study or author, suggesting that research conclusions can be completely disaggregated from the methods for the production of knowledge. A few examples:

"Schools have managed to stay open despite the violence because of an unwritten law to leave them alone - even the drug traffickers recognize that education is essential for children, sociologists say." (215)

"Sociologists say the flight of the middle class or affluent people- those most likely to have the money and foreign passports or visas to leave when things first go bad - can weaken both a country's economy and its social fabric.” (284)

"As people took sides, sociologists and other observers said the incident has focused attention on an insular culture rarely seen outside the firehouse." (As an interesting side note, the article goes on to quote only an anthropologist.) (285)

A possible explanation for such examples is that sociologists have been contacted by journalists to support the article, but didn't end up speaking on the record. A second possibility, in light of Dunwoody's (1980) interviews of reporters about their perceptions of social science, is that journalists feel comfortable summarizing sociological work without providing precise details or attribution because it won't "do too much damage.".

\section{Non Sociology-Focused Articles}

In the remaining one-third of articles $(n=62)$, sociology was ancillary to the main news event. The key word in just over three-quarters of the such articles was "sociology". These articles varied widely, and not always in ways that shed a positive light on the discipline: one sociology professor was charged with running a

\footnotetext{
${ }^{6}$ This finding does not differ significantly from Weiss and Singer's (1988) finding that eighteen percent of coverage of social science issues referenced a methodology.
} 
prostitution service; another professor was under investigation for allowing football players to take their core sociology courses as independent studies that never met; and a third story described a sociology major who was gunned down in New Orleans. On the other hand, athletes, politicians, and celebrities were mentioned as having backgrounds in sociology, and one article included Tulane's sociology department in a description of efforts to rebuild after hurricane Katrina.

Additionally, sociologists were also presented as acting or commenting in a nonresearch capacity, such as one professor who demanded that his university return a donation by former Enron executive Kenneth Lay, and a Harvard professor commenting on the departure of President Lawrence Summers. Several sociology students were also included in this category, including seniors at commencement and graduate students engaged in protests.

A third type of non-sociology focused articles are those in which sociology is invoked from a lay perspective. In some ways, this phenomenon strikes at the heart of the types of empirical questions that we should be asking before jumping into our call for more public sociology: how does the lay population understand our discipline? As Mesny (1998) argues, "lay appropriation of social science knowledge should be seen as a crucial manifestation of the reflexive process between social science knowledge and its "subjects."' In that vein, then, a description of nonacademic perceptions of sociology presents an excellent opportunity to empirically assess this phenomenon.

By and large, sociology was accurately employed by non-professionals:

'There are complex psychological and sociological reasons why HIV patients fall off their meds, such as domestic and economic problems.'

'People can attribute crime to failing schools, failing families. There's a bunch of sociological things you can put your finger on,' said police Sgt. Rich Ring, head of Orlando's homicide investigation unit. 'All we can do as police is say the biggest things are drugs and robbery, and we're going to take action on those issues.'

On the other hand, journalists and the people who they turned to for comment sometimes either had yet to develop a sense of the 'sociological imagination' or thought very little of this perspective on the social world.

[From a man who is selling fire-the-football-coach websites] "He calls the project an experiment in sports sociology and psychology, and says he was surprised that schools or even the coaches themselves didn't think first to secure those dot-coms and prevent what he called a "future PR nightmare",

"It seemed somehow appropriate, then, that word of his retirement from football leaked out when he was speaking to a sociology class. When he had an opinion, Bo could never keep it to himself."

From a college basketball player: 'I was analyzing the guys' nonverbal communication. I learned that in sociology.'

These excerpts suggest a lay understanding that trivializes issues of sociological concern, and moreover presents an unflattering portrayal of sociology as a discipline 
in which conjecture and opinion supersede careful empirical research. From this we can conclude that, while offering some degree of optimism, the lay understanding is somewhat mixed.

\section{So How Public Are We?}

As an exploratory beginning to analyzing sociology in the news, this project set out to answer two broadly defined questions. The first was, Under what circumstances is sociological expertise called upon in the news? Our findings suggest a few important implications in terms of themes, methodology, and institutional affiliation. To begin with, this analysis found that two-thirds of coverage contained a substantive focus on sociology and sociological research. In looking at the areas of sociology that appear in the news, we see that the themes range far and wide. While the most prevalent themes included politics, crime \& policing and religion, a panoply of other topics were represented, more or less spanning the breadth of sociological investigation. This supports our earlier point (also made by McNamee and Willis 1994) that the multi-faceted nature of sociology may preclude the press from thinking of sociologists as a "natural" source for any single topic.

Another area of consideration relates to the frequency with which a sociological study actually generates the news story. This occurred in approximately $9 \%$ of all articles. Although no obvious pattern emerges in terms of the areas of study that command attention - the research topics ranged from that factors that create a hit song to estimating the death toll in Darfur - there did appear to be a link between these articles and the prestige of the university with which the researchers were affiliated. Sociological research that drove coverage came from institutions such as Duke (three studies), Columbia (two studies), Stanford, Brown, New York University, Johns Hopkins University, and the University of Michigan. This is consistent with findings from other areas, which suggests that prestigious universities tend to acquire any number of benefits beyond what their academic output might suggest (e.g., Sine et al. 2003; Lee and Brinton 1996)

The notion of prestige emerged in our findings in another way. Among the articles that were driven by research, three of them referenced a specific journal- the only three times a journal was mentioned. ${ }^{7}$ The few references to a professional journal, the fact that one of them was JAMA, and the fact that three different journals were mentioned all suggest that, regardless of how sociology perceives the relative prestige of its own journals (i.e., the dominance of American Journal of Sociology and American Sociological Review), the news media may not see things the same way (Evans 1995). Furthermore, the fact that not a single ASA-sponsored publication appeared in our study supports our point that our professional society has a long way to go in sponsoring our public efforts.

Prestige is just one "space" within which patterns of sociological coverage emerged. We also identified a strong tendency toward international stories - just under $30 \%$ of our sample came from international datelines. To be sure, this bias is

\footnotetext{
${ }_{7}^{7}$ Journal of Marriage and the Family, Journal of Sociology, and Journal of the American Medical Association.
} 
largely a function of our methodological decision to analyze articles from the Associated Press rather than local news organizations. However, this is also consistent with Burawoy's (2005) assessment that nations around the world have a vibrant tradition of public sociology. As with most things, this does not happen organically, but rather as a result of structural conditions: Kalleberg (2008), for example, relates that Norwegian scholars across disciplines are required to demonstrate the public benefit of their scholarly research.

Of the few times that methodology was specifically mentioned, all but one story referenced quantitative methodology. This echoes prior research establishing that journalists use the $N$ of a study as a quick heuristic for determining the quality of the research (Schmierbach 2005), and additionally confirms the preference for scientificlike discourse for stories that draw upon research findings.

Beyond an investigation of sociologically-focused articles, we also posed the question regarding the circumstances under which sociology and sociologists were mentioned in the ancillary (that is, non-professional) sense. From an optimistic standpoint, we certainly identified some articles where sociological concepts and themes were used in ways that can be considered consistent with the discipline. Looking at the data slightly more cynically, stories about madams, cheaters, and murder victims in tandem with references to people who sell websites devoted to having coaches fired suggests that some work remains to be done in promoting a more consistent and positive sociological image in the press - public sociology that serves both the public and sociology.

\section{A Note on Methodology}

We are aware that the focus on Associated Press releases represents a relatively specific fraction of the print media that excludes news magazines, newspaper op-ed pieces, and locally-generated coverage. This choice was intentional. With a worldwide network of news production and dissemination, AP stories provide the biggest bang for the research buck by offering a snapshot of the news that most Americans encounter on a daily basis in their local newspapers or on news websites (e.g., Yahoo! News, MSN). However, it is important to include a note of caution in interpreting these results. The nature of wire stories is such that AP subscribers are free to (and frequently do) modify, remove, or supplement any portion of the text without having to seek permission (Siebel 2004). In other words, the fact that a given sociologist or sociological study appears in the release does not necessarily predict that they will appear uniformly across the country.

\section{Conclusion}

In this paper we have argued that, in light of the proliferation of calls to public sociology, the time has come to ascertain just how public we are. Preliminary analysis suggest that answering this question is far from straightforward.

One discrepancy pertains to the extent to sociologists themselves drive the coverage. One-third of these Associated Press articles referenced neither an 
empirical study nor a particular sociologist, and fewer than one in ten articles were generated by a specific research project. This finding both confirms our general assessment that sociology's message, profession, and members' perceptions hinder our ability to be publicized, and further recommends the need for additional analyses that empirically parse out the sociology-specific barriers to becoming more public. Future research should focus on the institutional and cultural barriers that preclude sociologists from becoming more active in the dissemination of their work.

Some interesting geographic findings emerged as well. There appear to be substantial discrepancies between how the profession is understood in the United States vs. other nations, particularly in the political realm. This finding strongly suggests the need for an explicit comparison of sociology's public presence across the globe.

Additionally, this analysis of sociology coverage yielded a wide array of research by subfield, thus shedding some light on the topics with which sociology is associated. Future efforts in this area might include interviews with journalists to question the types of news events that journalists associate with sociology.

If anything, this analysis raised more questions than it answered. What it did do, however, is establish the need for studies that with the same critical, empirical rigor that is applied to other research subjects. It is only through these efforts that we will be able to knowledgably move forward with the call for public sociology.

\section{References}

Adler, P. (1984). The Sociologist as celebrity: the role of the media in field research. Qualitative Sociology, 7(4), 310-326.

Associated Press. (2009). About AP: Facts and figures. http://www.ap.org/pages/about/about.html. Retrieved on April 27, 2009

Beck, U. (2005). How not to become a museum piece. The British Journal of Sociology, 56(3), 335-343.

Becker, H. S., \& Rau, W. C. (1992). Sociology in the 1990s. Society, 30, 70-74.

Best, J. (1986). Famous for fifteen minutes: notes on the researcher as newsmaker. Qualitative Sociology, 9(4), 372-382.

Best, J. (2004). Why don't they listen to us? Fashion notes on the imperial wardrobe. Social Problems, 51 (1), 154-160.

Boyd-Barrett, O., \& Rantanen, T. (2000). European national news agencies: the end of an era or a new beginning? Journalism, 1(1), 86-105.

Brady, D. (2004). Why public sociology may fail. Social Forces, 82(4), 1629-1638.

Brewer, P. R., \& Sigelman, L. (2002). Political scientists as color commentators: framing and expert commentary in media campaign coverage. The Harvard International Journal of Press/Politics, 7(1), 23-35.

Burawoy, M. (2004). Public sociologies: contradictions, dilemmas, and possibilities. Social Forces, 82(4), $1603-1618$.

Burawoy, M. (2005). 2004 american sociological association presidential address: for public sociology. The British Journal of Sociology, 56(2), 259-294.

Callaham, M., Wears, R. L., \& Weber, E. (2002). Journal prestige, publication bias, and other characteristics associated with citation of published studies in peer-reviewed journals. JAMA: Journal of the American Medical Association, 287(1), 2847-2850.

Danzger, M. H. (1975). Validating conflict data. American Sociological Review, 40, 570-584.

Dorfman, L., Wallack, L., \& Woodruff, K. (2005). More than a message: framing public health advocacy to change corporate practices. Health Education \& Behavior, 32(3), 320-336.

Dunning, E. (1994). The sociologist as media football: Reminiscences and preliminary reflections. In C. Haslam \& A. Bryman (Eds.), From social scientists meet the media. New York: Routledge. 
Dunwoody, S. (1980). The science writing inner club: a communication between science and the lay public. Science, Technology, \& Human Values, 5(30), 14-22.

Eisinga, R., Van Den Elzen, A., \& Verloo, M. (1999). Beliefs about the nature of sex/gender and ethnic inequality. International Journal of Comparative Sociology, 40(2), 231-250.

Ericson, R. (2005). Publicizing sociology. The British Journal of Sociology, 56(3), 365-372.

Evans, W. (1995). The mundane and the arcane: prestige media coverage of social and natural science. Journalism and Mass Communication Quarterly, 72(1), 168-177.

Fenton, N., Bryman, A., et al. (1997). 'Sod off and find us a boffin'; journalists and the social science conference. The Sociological Review, 45(1), 1-23.

George, L. (2001). What's fit to print: the effect of ownership concentration on product variety in daily newspaper markets. East Lansing, MI, Michigan State University: 40.

Glasser, T. L., Allen, D. S., \& Blanks, S. E. (1989). The influence of chain ownership on news play: a case study. Journalism Quarterly, 66, 607-614.

Jacobs, R. \& Townsley, E. (2004). Media intellectuals and public sociology: The case of op-eds in the New York times." Paper presented at the meetings of the American Sociological Association. San Francisco, CA.

Kalleberg, R. (2008). Norwegian sociologists as public intellectuals. Paper presented at the meetings of the American Sociological Association. Boston, MA.

Lee, S., \& Brinton, M. C. (1996). Elite education and social capital: the case of South Korea. Sociology of Education, 69(3), 177-192.

Luttbeg, N. R. (1983). News consensus: do U.S. newspapers mirror society's happenings? Journalism Quarterly, 60(3), 484-488. 578.

McNamee, S. J., \& Willis, C. L. (1994). Stratification in science: a comparison of publication patterns in four disciplines. Science Communication, 15(4), 396-416.

Merton, R. K., \& Wolfe, A. (1995). The cultural and social incorporation of sociological knowledge. The American Sociologist, 26(3), 15-39.

Mesny, A. (1998). The appropriation of social science knowledge by 'lay people': The development of a lay sociological imagination?" Doctoral Dissertation presented to Trinity College at the University of Cambridge.

Nielsen, F. (2004). The vacant 'we': remarks on public sociology. Social Forces, 82(4), 1619-1627.

Ortiz, S. M. (2007). Breaking out of academic isolation: the media odyssey of a sociologist. The American Sociologist, 38(3), 223-249.

Patterson, C. (2005). News agency dominance in international news on the internet. D. Skinner, J. R. Compton \& M. Gashe (eds.), From converging media, diverging politics. Lexington Books.

Petersen, J. C., Dukes, D., \& Van Valey, T. L. (2008). The practice of sociology: alternative futures for applied sociology. Journal of Applied Social Sciences, 7, 16-30.

Schmierbach, M. (2005). Method matters: the influence of methodology on journalists' assessments of social science research. Science Communication, 26(3), 269-287.

Siebel, C. (2004). Can tobacco control funding impact the associated press? An analysis of the relationship between SmokeLess States funding and AP coverage". Paper presented at the American Public Health Association. Washington, D.C.

Sine, W. D., Shane, S., \& Di Gregorio, D. (2003). The halo effect and technology licensing: the influence of institutional prestige on the licensing of university inventions. Management Science, 49(4), 478-496.

Small, M. L. (2008). Public sociology in the age of freakonomics: bringing a perspective back in. Paper presented at the Midwest Sociological Society. St. Louis, Missouri.

Smith K., Singer, R., \& Kromm, E. (In Press). Getting cancer research into the news: A communication case study centered on a US Comprehensive Cancer Center. Science Communication.

Soderlund, W. C., Krause, R. M., et al. (1991). Canadian daily newspaper editors' evaluation of international reporting. Canadian Journal of Communication, 16(1), 5-18.

Soloski, J. (1979). Economics and management: the real influence of newspaper groups'. Newspaper Research Journal, 1, 19-28.

Stacey, J. (2004). Marital suitors court social science spin-sters: the unwittingly conservative effects of public sociology. Social Problems, 51(1), 131-145.

Tittle, C. R. (2004). The arrogance of public sociology. Social Forces, 82(4), 1639-1643.

Vaughan, D. (2006). NASA Revisited: theory, analogy, and public sociology. American Journal of Sociology, 112(2), 353-393.

Weiss, C. H., \& Singer, E. (1988). Reporting of Social Science in the National Media. New York: Sage.

Woloshin, S., \& Schwartz, L. M. (2002). Press releases: translating research into news. Journal of the American Medical Association, 287(21), 2856-2858. 